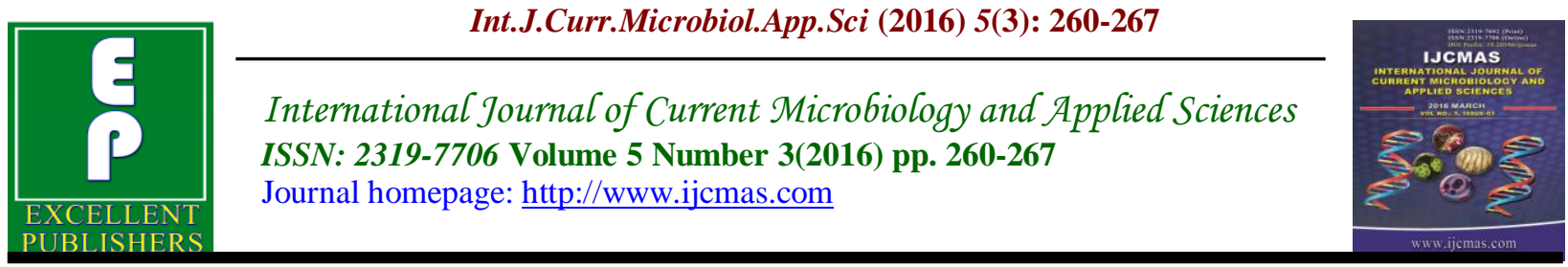

Original Research Article

http://dx.doi.org/10.20546/ijcmas.2016.503.032

\title{
Incidence and Molecular Characterization of Extended Spectrum of Beta Lactamase Producing Escherichia coli and Klebsiella pneumoniae isolated from Urinary Tract Infection in Patients with Type 2 Diabetes Mellitus
}

\author{
P. Ajay Kumar ${ }^{1 *}$ and C.S. VinodKumar ${ }^{2}$ \\ ${ }^{1}$ Research Scholar in Microbiology, Bharathiar University, Coimbatore, India \\ ${ }^{2}$ Department of Microbiology, S. S. Institute of Medical Sciences and Research Centre, \\ Davangere-577005, Karnataka, India \\ *Corresponding author
}

\begin{abstract}
A B S T R A C T
Keywords

Urinary tract

infection,

Type 2 diabetes

mellitus,

Extended

spectrum beta

lactamases,

TEM,

SHV,

CTX-M.

Article Info

Accepted:

15 February 2016

Available Online:

Predisposition to urinary tract infections (UTIs) in diabetes mellitus results from several factors. Susceptibility increases with longer duration and greater severity of diabetes. The continuous emergence of resistance to antimicrobial agents among the prevalent pathogens is the most dangerous threat for the treatment of infectious disease in type 2 diabetes mellitus. The production of $\beta$-lactamases is the major mechanism of bacterial resistance to B-lactam antibiotics which considered the most widely used class of antibiotic. Hence it is necessary to know the prevalence of ESBL so as to formulate a policy of empirical therapy in type 2 diabetes mellitus of the study was to characterization of ESBL genes in E. coli and Klebsiella pneumoniae from urinary tract infection among type 2 diabetic patients. A prospective study was carried out on 1560 diabetic patients with urinary tract infection during the period of July 2011 to June 2015. 277 Gram negative bacterial were isolated and identified by standard laboratory techniques. Antimicrobial sensitivity testing was performed on Mueller-Hinton agar plates with commercially available discs by the Kirby-Bauer disc diffusion method. 90 E.coli isolates and 64 K.pneumoniae were tested for ESBL production and PCR was performed using 5 sets of previous published primers to amplify type-specific ESBL genes, including CTX-M-1, CTX-M-2, CTX-M-9, TEM and SHV 46.7\% of E.coli and 59.4\% of K.pneumoniae were ESBL producers. Of the 42 ESBL-producing E. coli isolates, $38(90.5 \%)$ were positive for ESBL genes and $47.4 \%$ of the E.coli isolates had at least 2 ESBL genes. and CTX-M-9 was seen in 7 (18.4\%) isolates. Among K. pneumoniae, $32(84.2 \%)$ of the 38 isolates were positive for ESBL genes and The number of ESBL- producing $K$. pneumoniae with TEM was in $6(15.8 \%)$ isolates. This study highlights the high prevalence of ESBL production among $E$. coli and $K$. pneumoniae in the urinary tract infection among type 2 diabetic patients. Therefore, genotyping of ESBL is need of the hour for monitoring the significant ESBLs that can lead to treatment catastrophe in diabetic patients.
\end{abstract}




\section{Introduction}

The worldwide prevalence of Diabetes Mellitus (DM) has raised dramatically over the past two decades (Zaccardi, 2016). It affects more than 120 million people worldwide and it is estimated that it will affect 220 million by the year 2020.2 Patients with DM have a higher prevalence of Urinary Tract Infection (UTI) compared to nondiabetics. Symptomatic bacteriuria in patients with DM is serious and warrants proper clinical attention for diagnosis and treatment. UTI in diabetic patients are mostly considered as complicated (Ripsin CM, 2009. Gram negative bacteria are the predominant organism known to cause UTI in diabetes patients.

Antibiotics were first used to treat serious infections in the 1940s. Since then antibiotics have saved millions of lives and transformed modern medicine. During the last 75 years, however bacteria have shown the ability to become resistant to every antibiotic that have been developed and the more antibiotics are used the more quickly bacteria develop resistance. The number of reports about incidence of ESBL producing strains among clinical isolates has been steadily increasing over the past few years resulting in limitation of therapeutic options. Initially restricted to hospital-acquired infections, now they have also been isolated from infections in community (Arpin, 2003).

The resistance acquired by ESBL producing strains shoots from genetic point mutation and it is an unsolved, growing problem. In the near future both clinicians and microbiologist will be battling against ESBL producing strains due to their dynamic evolution and epidemiology in averting and controlling them (Jacoby, 2005, Rawat, 2010). One of the alarming natures of the ESBL producing strains is that they are resistant to antibiotics like cephalosporins, imipenem, aztronam etc. Bradford reported that ESBLs are undergoing continuous mutations, causing the development of new enzymes showing expanded substrate profiles (Bradford, 2001). Currently, over 150 ESBLs have been described in a worldwide distribution (Bush, 1995; Jacoby, 2005)). The ESBL genes are mostly plasmid encoded (Bonnet, 2000; Baraniak, 2002), andmost ESBL scan be divided into 3 genotypes: TEM, SHV and CTX-M (Philippon, 1989; Heritae, 1999, Chanawong, 2001; Bradford, 2001). K.pneumoniae was the major ESBL producer before 2000 and the predominant ESBL genotypes were TEM and SHV (Pagani, 2003). E.coli has now become an important ESBL carrier in Western countries. In addition, a genotype CTX-M has become more prevalent worldwide compared to the TEM and SHV genotypes (Tzouvelekis, 2000, Peirano, 2010).

Objective of the study was to characterization of ESBL genes in E. coli and Klebsiella sps from urinary tract infection among type 2 diabetic patients

\section{Materials and Methods}

A prospective study was carried out on 1560 diabetic patients with urinary tract infection during the period of July 2011 to June 2015.

277 Gram negative bacterial were isolated and identified by standard laboratory techniques (CLSI, 2015). Antimicrobial sensitivity testing was performed on Mueller-Hinton agar plates with commercially available discs (Hi-Media, Mumbai) by the Kirby-Bauer disc diffusion method (Bauer AW, 1996). The results were recorded and interpreted as per CLSI recommendations (CLSI, 2015). The analyzed drugs were the following agents: 
Ampicillin, Amikacin, Cotrimaxzole, Ciprofloxacin, Ceftriaxone, Nitrofurantoin, imipenem, meropenem, gentamicin, Sparfloxacin and Moxifloxacin.

\section{Detection of ESBL-Producing $E$. coli and K. pneumoniae}

\section{Double Disk Approximation Test for Screening}

The test organisms were applied on to a Mueller Hinton agar plate by adjusting turbidity to McFarland no 0.5 tube. Antibiotic discs of Amoxicillin / Clavulanic acid $(20 / 10 \mu \mathrm{g})$ and cefotaxime $(30 \mu \mathrm{g})$ were placed at a distance of $15 \mathrm{~mm}$ apart and incubated. Organisms that showed a clear extension of cefotaxime inhibition zone towards the disc containing Clavulanate were considered as ESBL producer (Mathur P, 2002). The organisms which were screened and found positive for ESBL production were subjected to confirmatory test.

\section{NCCLS Phenotypic Confirmatory Test}

Ceftazidime $(30 \mu \mathrm{g})$ and ceftazidime plus Clavulanic acid $(30 / 10 \mu \mathrm{g})$ were placed on Mueller Hinton agar and incubated. Organism was considered as ESBL producer if there was $\mathrm{a} \geq 5 \mathrm{~mm}$ increase in diameter of Ceftazidime plus Clavulanic disc and that of ceftazidime disc alone (Coudron PE, 1997, Bhattacharya S, 2006).

\section{Amp C Disk Test}

A lawn culture of E.coli ATCC 25922 was prepared on MHA plate. Sterile disks $(6 \mathrm{~mm})$ was moistened with sterile saline $(20 \mu \mathrm{l})$ and inoculated with several colonies of test organisms. The inoculated disk was then placed $5 \mathrm{~mm}$ beside a cefoxitin disc. Plates were incubated overnight at $35^{\circ} \mathrm{C}$. A positive test was appeared as a flattening or indentation of the cefoxitin inhibition zone in the vicinity of the test disc (Singhal S, 2005; Black JA, 2005). A negative test had an undisturbed zone

\section{Extraction of Plasmids}

A few colonies were suspended in $700 \mu \mathrm{L}$ of Tris-EDTA buffer (pH8.0). The suspensions were boiled for $10 \mathrm{~min}$ and subsequently centrifuged for $5 \mathrm{~min}$ at $13000 \mathrm{rpm}$. The supernatant, containing DNA, was transferred to new tubes and storedat $4^{\circ} \mathrm{C}$ for subsequent PCR analysis (Perez, 2002).

\section{Genotyping of ESBL}

PCR was performed using 5 sets of previous published primers to amplify type-specific ESBL genes, including CTX-M-1, CTXM-2, CTX-M-9, TEM and SHV (Poirel, 2001, Woodford, 2006). For detecting TEM or $\mathrm{SHV}$ genes, initial denaturation at $95^{\circ} \mathrm{C}$ for $10 \mathrm{~min}$, denaturation at $95^{\circ} \mathrm{C}$ for $1 \mathrm{~min}$, primer annealing at $56^{\circ} \mathrm{C}$ for $1 \mathrm{~min}$, and extension at $72^{\circ} \mathrm{C}$ for $1 \mathrm{~min}$, was repeated for 40 cycles; with a final extension at $72^{\circ} \mathrm{C}$ for $7 \mathrm{~min}$. For CTX-M gene, initial denaturation at $95^{\circ} \mathrm{C}$ for $10 \mathrm{~min}$, denaturation at $95^{\circ} \mathrm{C}$ for $1 \mathrm{~min}$, primer annealing at $60^{\circ} \mathrm{C}$ for $1 \mathrm{~min}$, and extension at $72^{\circ} \mathrm{C}$ for $1 \mathrm{~min}$, was repeated for 40cycles; a final extension at $72^{\circ} \mathrm{Cfor} 7$ min was carried out. The PCR products were analyzed using $2 \%$ agarose gel electrophoresis and visualized by staining with ethidium bromide.

\section{Results and Discussion}

ESBL-producing E.coli accounted for 42 of 90 isolates (46.7\%) and ESBL-producing K.pneumoniae accounted for 38 of 64isolates $(59.4 \%)$. 
The phenotypically identified ESBLproducing E.coli and $K$. pneumoniae were molecularly analyzed. Of the 42 ESBLproducing E. coli isolates, 38 (90.5\%) were positive for ESBL genes (Table 1). $47.4 \%$ of the isolates had at least 2 ESBL genes. The number of ESBL- producing E.coli with TEM, SHV, CTX-M-1, CTX-M-2 and CTXM-9 was $8(20.1 \%), 2(5.3 \%), 1(2.6 \%), 2$ $(5.3 \%)$ and $7(18.4 \%)$, respectively (Table 1). The number of ESBL-producing E. coli with TEM+SHV, CTX-M-1+SHV, CTX-M2+SHV, CTX-M-9+SHV, CTX-M-9+TEM and CTX-M-1+CTX-M-9+TEM was 3 (7.9\%), 2 (5.3\%), 3 (7.9\%), 1 (2.6\%), 8 $(21.1 \%), \quad 1 \quad(2.6 \%)$ and $1 \quad(0.6 \%)$, respectively.

For K. pneumoniae, $32(84.2 \%)$ of the 38 isolates were positive for ESBL genes (Table 2).

The number of ESBL- producing $K$. pneumoniae with TEM, SHV, CTX-M-1, CTX-M-2 and CTX-M-9 was $6(15.8 \%), 4$ $(12.5 \%), 3(9.4 \%), 1(3.1 \%)$ and $2(6.2 \%)$, respectively (Table 1).

The number of ESBL-producing $K$. pneumoniae with TEM+SHV, CTX-M2+SHV, CTX-M-9+SHV was not detected. CTX-M-1+SHV, CTX-M-9+TEM and CTX-M-1+CTX-M-9+TEM was 3 (9.4\%), $10(31.3 \%)$, and $2(5.2 \%)$ respectively.

To our knowledge, up to now, few articles have documented the molecular characterization of ESBL genes in the circulating E. coli from clinical specimen worldwide, but no article has documented on characterization of ESBL genes in E. coli and Klebsiella pneumoniae from urinary tract infection among type 2 diabetic patients. This characterization has a fundamental role in epidemiological studies, management, implementing, control and preventive measures of urinary tract infection among type 2 diabetic patients (Webster et al., 2011). Antibiotic-resistant E. coli and Klebsiella pneumoniae isolated from UTIs are increasingly found, and are a serious problem in many areas. Many strains are multi-resistant (Al-Agamy, 2013). In our study, $96 \%$ of E.coli and $88 \%$ of Klebsiella pneumoniae were noted $\mathrm{t} o$ be resistant to two or three groups of antibiotics tested. $34.1 \%$ of E.coli and $30.9 \%$ of Klebsiella pneumonia were the ESBL producers. ESBL producing Klebsiella pneumoniae generally appeared to be more resistant and showed an MDR phenotype at higher rate than ESBL producing E.coli. The high level of resistance seen to ciprofloxacin, ampicillin ceftazidime, gentamicin, sparfloxacin and cefotaxime is most likely due to selective pressure resulting from uncontrolled and inappropriate use of these agents in hospitals and in the country as a whole. This is promoted by the lack of an antibiotic policy and the availability of antibiotics sold over the counter in India.

The molecular classification of $\beta$-lactamases is based on the nucleotide and amino acid sequences in these enzymes. To date, four classes are recognized (A-D), correlating with the functional classification. Classes A, $\mathrm{C}$, and $\mathrm{D}$ act by a serine-based mechanism, whereas class $\mathrm{B}$ or metallo- $\beta$-lactamases need zinc for their action(Bush, 1995). Members of the family Enterobacteriaceae commonly express plasmid-encoded $\beta$ lactamases (e.g., TEM-1, TEM-2 and SHV1) which confer resistance to penicillins but not to expanded-spectrum cephalosporins. TEM-1 is the most commonly encountered beta-lactamase in Gram-negative bacteria. Up to $90 \%$ of ampicillin resistance in E. coli is due to the production of TEM-1 (Bradford, 1994) SHV-1 shares 68 percent of its amino acids with TEM-1 and has a similar overall structure. The SHV-1 beta- 
lactamase is most commonly found in $K$. pneumoniae and is responsible for up to
$20 \%$ of the plasmid-mediated ampicillin resistance in this species.

Table.1 Incidence of Extended Spectrum Beta Lactamases Producing Genes Among E.coli and Klebsiella pneumoniae Isolated from Urinary Tract Infection in Type 2 Diabetes Mellitus Patients

\begin{tabular}{|l|r|r|r|r|}
\hline \multirow{2}{*}{ ESBL Genotype } & \multicolumn{2}{|c|}{$\begin{array}{c}\text { E.coli } \\
(\mathrm{n}=42)\end{array}$} & \multicolumn{2}{c|}{$\begin{array}{c}\text { Klebsiella pneumoniae } \\
(\mathrm{n}=38)\end{array}$} \\
\hline & Number & Percentage & Number & \multicolumn{1}{c|}{ Percentage } \\
\hline TEM & 8 & 19 & 6 & 15.8 \\
\hline SHV & 2 & 4.8 & 4 & 10.5 \\
\hline CTX-M-1 & 1 & 2.4 & 3 & 7.9 \\
\hline CTX-M-2 & 3 & 7.1 & 1 & 2.6 \\
\hline CTX-M-9 & 9 & 21.4 & 7 & 18.4 \\
\hline TEM+SHV & 3 & 7.1 & 0 & 0 \\
\hline CTX-M-1+SHV & 2 & 4.8 & 3 & 7.9 \\
\hline CTX-M-2+SHV & 3 & 7.1 & 0 & 0 \\
\hline CTX-M-9+SHV & 1 & 2.4 & 0 & 0 \\
\hline CTX-M-9+TEM & 9 & 21.4 & 14 & 36.8 \\
\hline CTX-M-9+CTX- & & & & 5.2 \\
M1+TEM & 1 & 2.4 & 2 & \\
\hline
\end{tabular}

CTX-M-beta lactamases were named for their greater activity against cefotaxime than other oxyimino-beta-lactam substrates (e.g., ceftazidime, ceftriaxone, or cefepime). Rather than arising by mutation, they represent examples of plasmid acquisition of beta-lactamase genes normally found on the chromosome of Kluyvera species, a group of rarely pathogenic commensal organisms. These enzymes are not very closely related to TEM or SHV beta-lactamases in that they show only approximately $40 \%$ identity with these two commonly isolated betalactamases. More than $80 \mathrm{CTX}-\mathrm{M}$ enzymes are currently known. Despite their name, a few are more active on ceftazidime than cefotaxime (Bradford, 1994). They have mainly been found in strains of Salmonella enteric serovar Typhimurium and E. coli, but have also been described in other species of Enterobacteriaceae and are the predominant ESBL type in parts of South
America. (They are also seen in Eastern Europe) CTX-M-14, CTX-M-3 and CTX$\mathrm{M}-2$ are the most widespread. CTX-M-15 is currently (2006) the most widespread type in E. coli the UK and is widely prevalent in the community (Tzouvelekis, 2000).

An example of beta-lactamase CTX-M-15, along with ISEcp1, has been found to have recently transposed onto the chromosome of Klebsiella pneumoniae ATCC BAA-2146 (Woodford N, 2006)

In addition to the phenotypic screening tests for ESBLs detection, genotypic tests were done to confirm ESBL genes. Among 42 ESBL-producing E.coli isolates from urinary tract infection among type 2 diabetes mellitus, $90.5 \%$ carried several bla genes, which can probably account for a high-level -lactam-resistant phenotype. Similarly among 38 ESBL-producing K.pneumoniae 
isolates, $84.2 \%$ carried several bla genes. Although CTX-M types of ESBLs have been known for their rapid spread in Europe and Asia (Woodford, 2006; Pagani, 2003, Chanawong 2001), it was remarkable that in this study, $73.7 \%$ of ESBL producing E. coli and $68.8 \%$ of ESBL-producing $K$. pneumoniae isolates carried blaCTX-M. We therefore report the highest prevalence, to our knowledge, of blaCTX-M among ESBLproducing $E$. coli and ESBL-producing $K$. pneumoniae and demonstrate that CTX-Mtype ESBL is highly endemic in India among the urinary tract infection in type 2 diabetes mellitus. Further follow-up studies are still needed to apprise the detection of prevalence, source, mechanism of spread, mode of transfer of ESBL determinants of resistance and/or ESBL-producing organisms for improved perception that enables the institution of strict public health measures and modified antimicrobial therapeutic strategies to eradicate or at least to hamper the spread of ESBL resistance determinants and ESBL-producers.

\section{Acknowledgement}

Authors would like to acknowledge Department of Biotechnology \& microbiology, Bharathiar University for the facilities and the support.

\section{References}

Al Johani, S.M., Akhter, J., Balkhy, H., ElSaed, A., Younan, M., Memish, Z. 2010. Prevalence of antimicrobial resistance among gram-negative isolates inan adult intensive care unit at a tertiary care center in Saudi Arabia. Ann. Saudi. Med., 30(5): 364.

Al-Agamy, M.H.M., M.S.E., Wiegand, I. 2006. First description of CTX-M beta-lactamase-producing clinical Escherichia coli isolates from Egypt.
Int. J. Antimicrob. Ages., 27: 545548.

Arpin, C., Dubois, V., Coulange, L., et al. 2003. Extended-spectrum betalactamase-producing

Enterobacteriaceae in community and private health care centers. Antimicrob. Agents Chemother., 47: 3506-3514.

Baraniak, A., Fiett, J., Sulikowska, A., Hryniewicz, W., Gniadkowski, M. 2002. Countrywide spread of CTX-M3 extended-spectrum betalactamaseproducing microorganisms of the family Enterobacteriaceaein Poland. Antimicrob. Agents Chemother., 46: 151-159.

Bauer, A.W., Kirby, W.M.M., Sherris, J.C., Jurek, M. $1966 . \quad$ Antibiotic susceptibility testing by a standardized disc method. Amer. J. Clin. Pathol., 45: 493-496.

Bhattacharya, S. 2006. Extended spectrum $\beta$-lactamases from petridish to the patient. Ind. J. Med. Microbial., 24(1): 20-24.

Black, J.A., Moland, E.S., Thomson, K.S. 2005. Amp C disk test for detection of plasmid mediated Amp C $\beta$ lactamases. J. Clin. Microbiol., 43(7): 3110-13.

Bonnet, R. 2004. Growing group of extended-spectrum betalactamases: the CTX-M enzymes. Antimicrob. Agents Chemother., 48: 1-14.

Bonnet, R., Sampaio, J.L., Labia, R., De Champs, C., Sirot, D., Chanal, C., Sirot, J. 2000. A novel CTX-M betalactamase (CTX-M-8) incefotaximeresistant Enterobacteriaceae isolated in Brazil. Antimicrob. Agents Chemother., 44: 1936-1942.

Bradford, P.A., Cherubin, C.E., Idemyor, V., Rasmussen, B.A., Bush, K. 1994. Multiply resistant Klebsiella pneumoniae strains from two 
Chicago Hospitals: identification of the extended-spectrumTEM-12 and TEM-10 ceftazidime-hydrolyzing $\beta$ lactamases in asingle isolate. Antimicrob. Agents Chemother., 38: 761-766.

Bradford, P.A. 2001. Extended-spectrum lactamases in the 21st century: characterization, epidemiology, and detection of this important resistance threat. Clin. Microbiol. Rev., 14: 933-951.

Bush, K., Jacoby, G.A., Medeiros, A.A. 1995. A functional classification scheme for beta-lactamases and its correlation with molecular structure. Antimicrob. Agents Chemother., 39(6): 1211-33.

Chanawong, A., Zali, F.H.M., Heritage, J., Lutitanond, A., Hawkey, P. M. 2001. SHV-12, SHV-5, SHV-2a and VEB-1 extended-spectrum -lactamasesin Gram-negative bacteria isolated in a university hospital in Thailand. $J$. Antimicrob. Chemother., 48: 839852.

CLSI. 2015. Performance Standards for Antimicrobial Susceptibility Testing; 23rd Informational Supplement M100-S23. Wayne, PA. Clin. Lab. Standards Institute.

Coudron, P.E., Moland, E.S., Sanders, C.C. 1997. Occurrence and Detection of Extended-Spectrum B-lactamases in members of the family Enterobacteriaceae at a Veterans Medical Center: Seek and You May Find. J. Clin. Microbiol., 35(10): 2593-7.

Heritae, J., M'Zali, F.H., Gascoyne-Binzi, D. 1999. Evolution and spread of SHV extended-spectrum $\beta$ lactamases in Gram-negativebacteria. J. Antimicrob. Chemother., 199, 44(3): 309-8.
Jacoby, G.A., Munoz-Price, L.S. 2005. The new beta-lactamases. $N$. Engl. J. Med., 352(4): 380-91.

Mathur, P., Kapil, A., Das, B., Dhawan, B. 2002. Prevalence of extended spectrum beta lactamase producing Gram negative bacteria in a tertiary care hospital. Ind. J. Med. Res., 115: 153-7.

Pagani, L., Dell Amico, E., Migliavacca, R., D Andrea, M.M., Giacobone, E., Amicosante, G., Romero, E., Rossolini, G.M. 2003. MultipleCTXM-type extended-spectrum betalactamases in nosocomial isolatesof Enterobacteriaceae from a hospital in northern Italy. J. Clin. Microbiol., 41: 4264-4269.

Peirano, G., Pitout, J.D. 2010. Molecular epidemiology of Escherichia coli producing CTX-M beta-lactamases: the worldwide emergence of clone ST131 O25: H4. Int. J. Antimicrob. Agents, 35: 316-321.

Perez-Perez, F.J., Hanson, N.D. 2002. Detection of plasmidmediated AmpC beta-lactamase genes in clinical isolates by usingmultiplex PCR. $J$. Clin. Microbiol., 40: 2153-2162.

Philippon, A., Labia, R., Jacoby, G. 1989. Extended-spectrum beta-lactamases. Antimicrob. Agents Chemother. 33(8): 1131.

Poirel, L., Naas, T., Thomas, I.Le., Karim, A., Bingen, E., Nordmann, P. 2001. CTX-M-type extended-spectrum beta-lactamase that hydrolyzes ceftazidime through a single amino acid substitution in the omega loop. Antimicrob. Agents Chemother., 45: 3355-3361.

Rawat, D., Nair, D. 2010. Extendedspectrum $\beta$-lactamases in Gram negative bacteria. J. Glob. Infect. Dis., 2(3): 263. 
Ripsin, C.M., Kang, H., Urban, R.J. 2009. Management of blood glucose in type 2 diabetes mellitus. Am. Fam. Physician, 79(1): 29-36.

Singhal, S., Mathur, T., Khan, S., Upadhyay, D.J. 2005. Evaluation of method for Amp C $\beta$-lactamases in Gram negative clinical isolate from tertiary care hospital. Ind. J. Med. Microbiol., 23(2): 120-124.

Sirot, D., Sirot, J., Labia, R., et al. 1987. Transferable resistance to thirdgeneration cephalosporins in clinical isolates of Klebsiella pneumoniae: identificationof CTX-1, a novel blactamase. J. Antimicrob. Chemother., 20: 323-34.

Tzouvelekis, L.S., Tzelepi, E., Tassios, P.T., Legakis, N.J. 2000.CTX-M-type beta-lactamases: an emerging group of extended spectrum enzymes. Int. $J$. Antimicrob. Agents, 14: 137-142.
Webster, M.W. 2011. Clinical practice and implications of recent diabetes trials. Curr. Opinion in Cardiol., 26(4): 288-93.

Woodford, N., Ward, E., Kaufmann, M.E., et al. 2006. Molecular characterization of Escherichia coli isolates producing CTX-M-15 extendedspectrum $\beta$-lactamase (ESBL) in the United Kingdom. Health Protection Agency, Retrieved 11-19.

Zaccardi, F., Webb, D.R., Yates, T., Davies, M.J. 2016. Pathophysiology of type 1 and type 2 diabetes mellitus: a 90year perspective. Postgraduate Med. J., 92(1084): 63-9.

Zhang, Y., Yang, J., Ye, L., Luo, Y., Wang, W., Zhou, W., Cui, Z., Han, L. 2012.Characterization of clinical multidrug-resistant Escherichia coli and Klebsiella pneumoniae isolates, 2007-2009, China. Microb. Drug Resist., 18: 465-470.

\section{How to cite this article:}

Ajay Kumar, P., VinodKumar, C.S. 2016. Incidence and Molecular Characterization of Extended Spectrum of Beta Lactamase Producing Escherichia coli and Klebsiella pneumoniae isolated from Urinary Tract Infection in Patients with Type 2 Diabetes Mellitus. Int.J.Curr.Microbiol.App.Sci. 5(3): 260-267. doi: http://dx.doi.org/10.20546/ijcmas.2016.503.032 